\title{
Essay for the CIHR/CMAJ award: the role of low-molecular- weight heparin therapy venous thromboembolism
}

\author{
Russell Hull MBBS MSc
}

See related articles by Kelsall at www.cmaj.ca/cgi/doi/10.1503/cmaj.110255, by Frank and colleagues at www.cmaj.ca/cgi/doi/10.1503/cmaj.110358, and by Devereaux and colleagues at www.cmaj.ca/cgi/doi/10.1503/cmaj.110292.

Competing interests:

Russell Hull is a consultant

for Leo Pharma, Merck,

Pfizer, GlaxoSmithKline,

Sanofi Aventis and Bayer.

$\mathrm{He}$ has received grants from

Leo Pharma, Dupont,

Pharmion and Pharmacia.

Correspondence to:

Dr. Russell Hull,

rdhull@ucalgary.ca

CMAJ 2011. DOI:10.1503

/cmaj.110364
Russell Hull, the POISE-1 investigators, and Cyril Frank and colleagues for the Alberta Bone and Joint Health Institute are the highest-ranking winners of the 2009-2010 CIHR/CMAJ competition for the Top Achievements in Health Research. Dr. Hull describes his work in treatments for venous thrombosis in the following essay. The essay by Dr. Devereaux and colleagues, the essay by Dr. Frank and colleagues, and synopses of the other three winning achievements are available at cmaj.ca.

$\mathrm{T}$ here is a need for an effective and safe alternative to therapy with vitamin $\mathrm{K}$ antagonists in a broad spectrum of patients with venous thrombosis. Long-term use of low-molecular-weight heparin, although administered subcutaneously, may be a viable option. A key concern with long-term use of vitamin $\mathrm{K}$ antagonists is harm resulting from hemorrhagic complications. Aggregate data reported in a systematic review identified that long-term use of low-molecular-weight heparin may cause less bleeding, but the authors cautioned that further study was needed in individual trial settings to determine where safety was improved. ${ }^{1}$ These authors also reported uncer- tainty on the efficacy of long-term use of lowmolecular-weight heparin for preventing recurrent venous thromboembolism, but they noted that the doses used in some trials may have resulted in inadequate therapy. ${ }^{1}$

Research evaluating the treatment of deep vein thrombosis with low-molecular-weight heparin that had shown a reduction in mortality among patients with cancer led to renewed interest in the effect of these agents on the survival of such patients. ${ }^{2}$ Randomized trials were needed to investigate the effectiveness and safety of the long-term use of low-molecular-weight heparin therapy for patients with both venous thromboembolism and cancer.

\section{Development of the program}

Under the auspices of the Medical Research Counsel (now the Canadian Institutes of Health Research [CIHR]) and with an operating grant for industry-partnered collaborative research, a multicentre randomized clinical trial program was initiated in 1994 to address the substantive clinical need for an alternate to vitamin $\mathrm{K}$ antagonist therapy, particularly among patients with cancer who also required treatment for venous thromboembolism.

When this research program was launched, there were no data available from randomized controlled trials evaluating long-term therapy with low-molecular-weight heparin versus vitamin $\mathrm{K}$ antagonist therapy. The clinical need for such a research program was based on the intial results from studies that showed long-term use of low-molecular-weight heparin among patients with venous thromboembolism was associated with a reduction in cancer mortality. ${ }^{2}$

The findings of the clinical trial program are reported by Hull and colleagues in three papers published in the American Journal of Medicine. ${ }^{3-5}$ 
In summary, 737 patients were enrolled in a multicentre, randomized, open-label clinical trial using objective outcome measures for both efficacy and safety that compared therapies (tinzaparin or usual care) for three months. ${ }^{4}$ The patients were divided into two groups: patients without cancer who required long-term treatment for venous thromboembolism, and patients with cancer who required long-term treatment for venous thromboembolism. The patients with cancer were stratified separately at the time of randomization. Outcomes were assessed at 3 and 12 months.

\section{Key findings}

Of the 369 patients receiving tinzaparin, 18 (4.9\%) had recurrent venous thromboembolism at three months, compared with $21(5.7 \%)$ of the 368 patients receiving usual care (absolute difference $-0.8 \%, 95 \%$ confidence interval $[\mathrm{CI}]-4.1$ to 2.4 ). Hemorrhagic complications, using the definitions endorsed by the International Society on Thrombosis and Hemostasis ${ }^{6}$ and developed by Hull and coworkers in $1982,{ }^{7}$ occurred less often in the low-molecular-weight heparin group, largely because of a lower incidence of minor bleeding. Forty-eight of the 369 patients $(13 \%)$ in the lowmolecular-weight heparin group had bleeding versus 73 (19.8\%) of the 368 patients receiving usual anticoagulation therapy (absolute difference $-6.8 \%, p=0.011$; risk ratio $=0.66$ ). New major bleeding events ended early (by day $23, p=$ 0.034 ) for patients receiving low-molecularweight heparin, but such events persisted throughout the study for patients receiving vitamin $\mathrm{K}$ antagonists. Mortality was not significantly different between therapy groups.

This study showed that the effectiveness of low-molecular-weight heparin is similar to that of vitamin $\mathrm{K}$ antagonists for preventing recurrent venous thromboembolism in a broad spectrum of patients. However, low-molecular-weight heparin therapy causes less harm than the vitamin $\mathrm{K}$ antagonist, thus expanding the therapeutic options for patients with proximal deep vein thrombosis. These results suggest the possibility of a broader role for long-term treatment with low-molecularweight heparin in selected patients.

A prospective evaluation of patients with cancer and proximal venous thrombosis was also done, as patients with cancer were randomized separately within the overall population. This allowed us to study the effectiveness and safety of long-term use of low-molecularweight heparin specifically for this population. ${ }^{3}$ Of 200 patients in this group, 100 received tinzaparin and 100 received usual care. At 12 months, 16 of 100 patients receiving usual care had recur- rent thromboembolism, versus 7 of 100 patients receiving low-molecular-weight heparin ( $p=$ 0.044 ; risk ratio $=0.44$; absolute difference -9.0 , $95 \% \mathrm{CI}-21.7$ to -0.7$)$. Bleeding, largely minor, occurred in 27 of the patients receiving tinzaparin and in 24 of the patients receiving usual care (absolute difference -3.0, 95\% CI -9.1 to 15.1).

Among patients without additional risk factors for bleeding at the time of randomization, major bleeding occurred in none of the 51 patients receiving tinzaparin and in only $1(2.1 \%)$ of the 48 patients receiving usual care. The high mortality at one year reflected the severity of the cancers; $47 \%$ of the patients in each group died. These findings confirmed the limited, but benchmarked, data in the literature that had been reported during the conduct, analysis and reporting phase of our trial (e.g., Lee and colleagues ${ }^{8}$ ) and showed that low-molecular-weight heparin is more effective than vitamin $\mathrm{K}$ antagonist therapy for preventing recurrent venous thromboembolism in patients with both cancer and proximal venous thrombosis.

\section{Impact of the program}

Based on the earlier findings of Hull and colleagues, ${ }^{9,10}$ Lee and colleagues ${ }^{8}$ and Buller and colleagues ${ }^{11}$ concluded that the evidence supported the use of low-molecular-weight heparin for at least the first three to six months of longterm treatment for most patients with deep vein thrombosis and cancer (Grade 1A). Subsequently, the 2008 report by the 8th American College of Chest Physicians' Conference on Antithrombotic and Thrombolytic Therapy (reported by Kearon and colleagues) ${ }^{12}$ recommended use of low-molecular-weight heparin as the long-term treatment of choice in patients with cancer and deep vein thrombosis (Grade 1A).

The American College of Chest Physicians' recommendation s $^{11,12}$ have resulted in widespread use of long-term low-molecular-weight heparin therapy in patients with venous thromboembolism and cancer. This therapy has also been endorsed in a guideline by the American Society of Clinical Oncology,$^{13}$ which reported and cited the CIHR-supported data, and by several international guidelines. ${ }^{14-16}$ The recommendations made in these consensus guidelines are widely accepted.

\section{Future directions}

Continued research using randomized clinical trials is underway to evaluate the potential benefit that low-molecular-weight heparin therapy may have on mortality among patients with cancer but 
without deep vein thrombosis. Because aggregate data suggest that low-molecular-weight heparin may act as an adjunct and modify the natural history of cancer, additional research has been started to evaluate the impact of this therapy as an adjunct in the treatment of patients with malignancy.

\section{References}

1. Van der Heijden JF, Hutten BA, Büller HR, et al. Vitamin K antagonist or low-molecular-weight heparin for the long-term treatment of venous thromboembolism [review]. Cochrane Database Syst Rev 2002;(1):CD002001.0.

2. Green D, Hull RD, Brant RF, et al. Lower mortality in cancer patients treated with low-molecular-weight heparin versus standard heparin. Lancet 1992;339:1476.

3. Hull RD, Pineo GF. Brant RF, et al.; for the LITE Trial Investigators. Long-term low-molecular-weight heparin versus usual care in proximal-vein thrombosis patients with cancer. Am J Med 2006;119:1062-72.

4. Hull RD, Pineo GF, Brant RF, et al.; LITE Trial Investigators. Self-managed long-term low-molecular-weight heparin therapy: the balance of benefits and harms. Am J Med 2007;120:72-82.

5. Hull RD, Pineo GF, Brant R, et al.; LITE Trial Investigators. Home therapy of venous thrombosis with long-term LMWH versus usual care: patient satisfaction and postthrombotic syndrome. Am J Med 2009;122:762-9.

6. Schulman S, Kearon C; Scientific and Standardization Committee of the International Society on Thrombosis and Haemostasis. Definition of major bleeding in clinical investigations of antihemostatic medicinal products in nonsurgical patients. J Thromb Haemost 2005;3:692-4

7. Hull R, Hirsh J, Jay R, et al. Different intensities of oral antico- agulant therapy in the treatment of proximal-vein thrombosis. N Engl J Med 1982;307:1676-81.

8. Lee AYY, Levine MN, Baker RI, et al.; CLOT Investigators. Low-molecular-weight heparin versus a coumarin for the prevention of recurrent venous thromboembolism in patients with cancer. N Engl J Med 2003;349:146-53.

9. Hull R, Pineo GF, Mah A, et al. A randomized trial evaluating long-term low-molecular-weight heparin therapy for three months vs. intravenous heparin followed by warfarin sodium in patients with current cancer [abstract]. Blood 2002;100:148a.

10. Hull R, Pineo GF, Mah A, et al. A randomized trial evaluating long-term low-molecular-weight heparin therapy for three months vs. intravenous heparin followed by warfarin sodium in patients with current cancer [abstract]. J Thromb Haemost 2003;1(Suppl.1):137a.

11. Büller HR, Agnelli G, Hull RD,et al. Antithrombotic therapy for venous thromboembolic disease. Chest 2004;126:401S-28S.

12. Kearon C, Kahn SR, Agnelli G, et al. Antithrombotic therapy for venous thromboembolic disease. Chest 2008; 133:454S-545S

13. Lyman GH, Khorana AA, Falanga A, et al. Francis. American Society of Clinical Oncology Guideline: recommendations for venous thromboembolism prophylaxis and treatment in patients with cancer. J Clin Oncol 2007;25:34.

14. Wagman LD, Baird MF, Bennett CL, et al.; National Comprehensive Cancer Network. Venous thromboembolic disease. Clinical Practice Guidelines in Oncology. J Natl Compr Can Netw 2008;6: 716-53.

15. Mandalà M, Falanga A, Piccioli A, et al. Venous thromboembolism and cancer: Guidelines of the Italian Association of Medical Oncology (AIOM). Crit Rev Oncol Hematol 2006;59:194-204.

16. Peterson LJ. Anticoagulation therapy for prevention and treatment of venous thromboembolic events in caner patients: a review of current guidelines. Cancer Treat Rev 2009;35:754-64.

Affiliation: From the Thrombosis Research Unit, University of Calgary, Calgary, Alta. 